\title{
Effect of antagonistic yeast XL-1 on resistance-associated enzyme activities in postharvest cantaloupe
}

\author{
C.-H. Shan ${ }^{1,2}$, W. Chen ${ }^{1}$, H. Zhang1, F.-X. Tang ${ }^{2}$ and J.-M. Tong ${ }^{2}$ \\ ${ }^{1}$ Food College, Jiangnan University, Wuxi, Jiangsu, China \\ ${ }^{2}$ Food College, Shihezi University, Shihezi, Xinjiang, China \\ Corresponding author: W. Chen \\ E-mail: chenwei_sch@163.com
}

Genet. Mol. Res. 13 (3): 6253-6258 (2014)

Received July 29, 2013

Accepted February 4, 2014

Published August 15, 2014

DOI http://dx.doi.org/10.4238/2014.August.15.8

\begin{abstract}
The effect of the antagonistic yeast XL-1 on resistanceassociated enzyme activities in postharvest cantaloupe was studied by inoculating the antagonistic yeast XL-1. Cantaloupes were sterilized, dried in air, and soaked in antagonistic yeast treatment liquid for 30 s. After drying in air, the cantaloupe was stored at room temperature $\left(2^{\circ}-5^{\circ} \mathrm{C}\right)$. The activities of resistance-associated enzymes in cantaloupe like polyphenol oxidase, $\beta$-1,3-glucanase, peroxidase, and superoxide dismutase were measured every 7 days. Our results indicated that the antagonistic yeast XL-1 significantly improved the activity of $\beta-1,3-$ glucanase and chitinase to promote the disease resistance of postharvest cantaloupe.
\end{abstract}

Key words: Antagonistic yeast XL-1; $\beta$-1,3-glucanase; Chitinase; Peroxidase 


\section{INTRODUCTION}

Some resistance-associated enzymes play important roles in the ability of postharvest fruits and vegetables to resist infection from pathogenic bacteria during storage (Schneider and Ullrich, 1994). Polyphenol oxidase (PPO) catalyzes the formation of lignin and quinones to construct a protective shield and protect cells from bacterial infection. Peroxidase (POD) plays a role in the last step of the lignin biosynthesis reaction to catalyze $\mathrm{H}_{2} \mathrm{O}_{2}$ decomposition. Superoxide dismutase (SOD) can eliminate oxygen-free radicals, which are produced during $\mathrm{O}^{2}$ reduction to $\mathrm{H}_{2} \mathrm{O}$ or biomolecular autoxidation, and induce production of $\mathrm{H}_{2} \mathrm{O}_{2}$ and hydroxyl radicals; these substances are toxic to cells, especially the membrane (Abeles and Biles, 1991).

Xinjiang is located in the hinterland of the Eurasian continental bridge, the weather of which is the typical continental climate with a significant temperature difference between day and night and a long duration of sunshine to form cantaloupe resource ascendancy. Cantaloupes are famous domestic and overseas for their large fruit, strong fragrance, and beautiful tempting color. They are sold to eastern coastal developed regions in China and exported to European and American countries. Until recently, there were only simple methods for cantaloupe storage like mound storage, sand storage, cellar storage, simple refrigeration, storage by chemical medicine, and painting film, but most of these methods involve preservation with traditional chemical antiseptics. The aim of this study was to screen antagonistic yeast in disease protection in postharvest cantaloupes. The effect of the antagonistic yeast on resistance-associated enzyme activities in postharvest cantaloupe was analyzed to provide evidence for the antagonistic mechanism of cantaloupe antagonistic yeast as well as postharvest disease protection and cure.

\section{MATERIAL AND METHODS}

\section{Materials}

Cantaloupes were harvested in the Altai region of Xinjiang. Cantaloupes with similar size and shape, no mechanical injury, and no disease were selected for this study. Antagonistic yeast was isolated by the project group and named XL-1.

\section{Reagents and instruments}

Reagents included glucose (anhydrous), beef extract (anhydrous), yeast powder (anhydrous), agarose (anhydrous), and $\mathrm{CaCl}_{2}$ (anhydrous). Equipment included a digital stainless steel electric incubator, biochemical incubator, microscope, electric oven, refrigerator, pipette, ultraviolet/visible light spectrophotometer, and clean benches.

\section{Methods}

Nutrient yeast dextrose broth (NYDB) medium comprised $8 \mathrm{~g}$ beef extract, $5 \mathrm{~g}$ yeast powder, $10 \mathrm{~g}$ glucose, and $1000 \mathrm{~mL}$ distilled water at the natural $\mathrm{pH}$; the medium was sterilized at $121^{\circ} \mathrm{C}$ for $20 \mathrm{~min}$. 


\section{Antagonistic yeast treatment liquid preparation}

XL-1 yeast was activated, inoculated into a flask including $100 \mathrm{~mL}$ NYDB, and incubated at $28^{\circ} \mathrm{C}$ and $250 \mathrm{rpm}$ for $42 \mathrm{~h}$. Zymolysis liquid was centrifuged at $6000 \mathrm{rpm}$ for 5 min to collect yeast. Yeast was washed with distilled water to prepare the yeast suspension. Yeast cells were counted using a hemocytometer and prepared as the following treatment liquids: 1) yeast suspension: $1 \times 10^{8}$ cells $/ \mathrm{mL}$ in distilled water and 2) yeast suspension including $2 \% \mathrm{CaCl}_{2}: 1 \times 10^{8}$ cells $/ \mathrm{mL}$ in distilled water and $2 \% \mathrm{CaCl}_{2}$.

\section{Resistance-associated enzyme activity measurement in cantaloupe}

After being sterilized, cantaloupes were dried in air and soaked in the above treatment liquids for $30 \mathrm{~s}$. After drying in air, cantaloupes were stored at room temperature $\left(2^{\circ}\right.$ $5^{\circ} \mathrm{C}$ ), and enzyme activities in cantaloupe were measured every 7 days with the distilled water treatment as a control. Cantaloupe flesh $(10 \mathrm{~g})$ was added to $50 \mathrm{~mL}$ phosphate buffer including $1.33 \mathrm{mM}$ ethylenediaminetetraacetic acid and $1 \mathrm{~g} / \mathrm{L}$ polyvinylpolypyrrolidone, $\mathrm{pH} 7.8$, put in an ice bath, homogenized, and centrifuged at $10,000 \mathrm{rpm}$ for $20 \mathrm{~min}$, and the supernatant was used to measure the enzyme activity. The activities of chitinase and $\beta$-1,3-glucanase were measured according to the Abeles method. The enzyme amount that increased the absorbance of the reaction solution at $524 \mathrm{~nm}$ by 0.001 per min was calculated as 1 chitinase activity unit, and the enzyme amount that produced $1 \mathrm{mg}$ glucose per $\mathrm{h}$ was calculated as $1 \beta$-1,3-glucanase activity unit. The phenylalanine ammonialyase (PAL) activity was measured using Zucker's method, and the enzyme amount that increased the absorbance of the reaction solution at $290 \mathrm{~nm}$ by $0.001 \mathrm{per} \mathrm{h}$ was calculated as 1 PAL activity unit. The POD activity was measured by Kochba's method, and the enzyme amount that increased the absorbance of the reaction solution at $470 \mathrm{~nm}$ by 0.001 per min was calculated as 1 POD activity unit. All enzyme activity results are reported as $\mathrm{U} \cdot \mathrm{g}$ fresh weight $\mathrm{t}^{-1} \cdot \mathrm{min}^{-1}$.

Each measurement was calculated in triplicate. All data were analyzed by SPSS 12.0. Duncan's multiple comparison method was conducted with $5 \%$ considered a significant difference and $1 \%$ considered an extremely significant difference.

\section{RESULTS}

\section{Effect of XL-1 treatment on PPO activity in cantaloupe}

The PPO activity in cantaloupe was improved and induced by antagonistic yeast XL-1 treatment. The PPO activity in cantaloupe reached its peak after being treated with $\mathrm{XL}-1+2 \% \mathrm{CaCl}_{2}$ for 7 days and was significantly higher than that in the control group. The PPO activity in cantaloupe that was only treated with XL-1 showed a similar tendency, but with a smooth variance, and was also significantly higher than that in the control group, as shown in Figure 1.

\section{Effect of XL-1 and $2 \% \mathrm{CaCl}_{2}$ on $\beta-1,3$-glucanase activity}

As shown in Figure 2, the $\beta$-1,3-glucanase activity was induced and enhanced by antagonistic yeast XL-1 treatment. The $\beta-1,3$-glucanase activity reached its peak after antago- 
nistic yeast $\mathrm{XL}-1+2 \% \mathrm{CaCl}_{2}$ treatment for 35 days and was significantly higher than that in the control group. The $\beta$-1,3-glucanase activity in cantaloupe that was only treated with XL-1 showed a similar tendency, but with a smooth variance, and was also significantly higher than that in the control group.

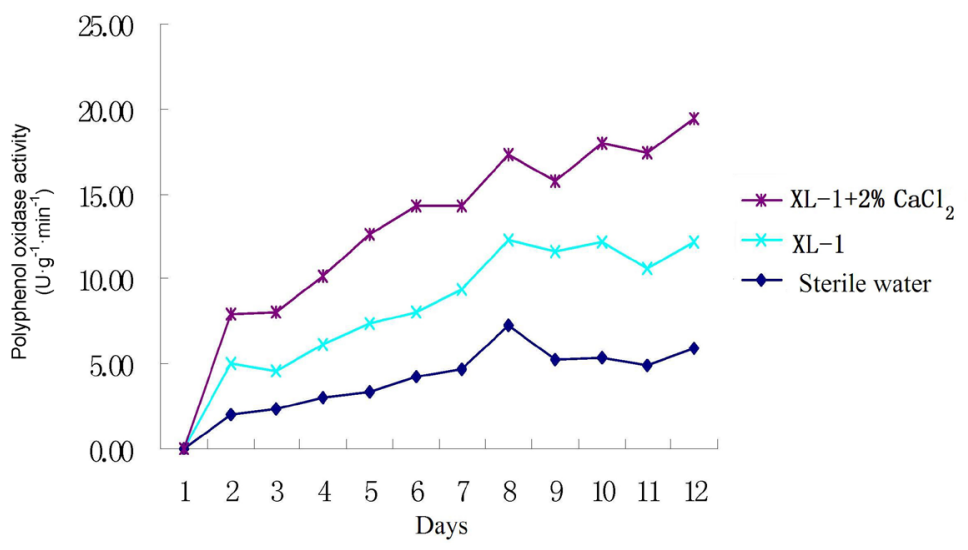

Figure 1. Effect of XL-1 treatment on polyphenol oxidase activity in cantaloupe.

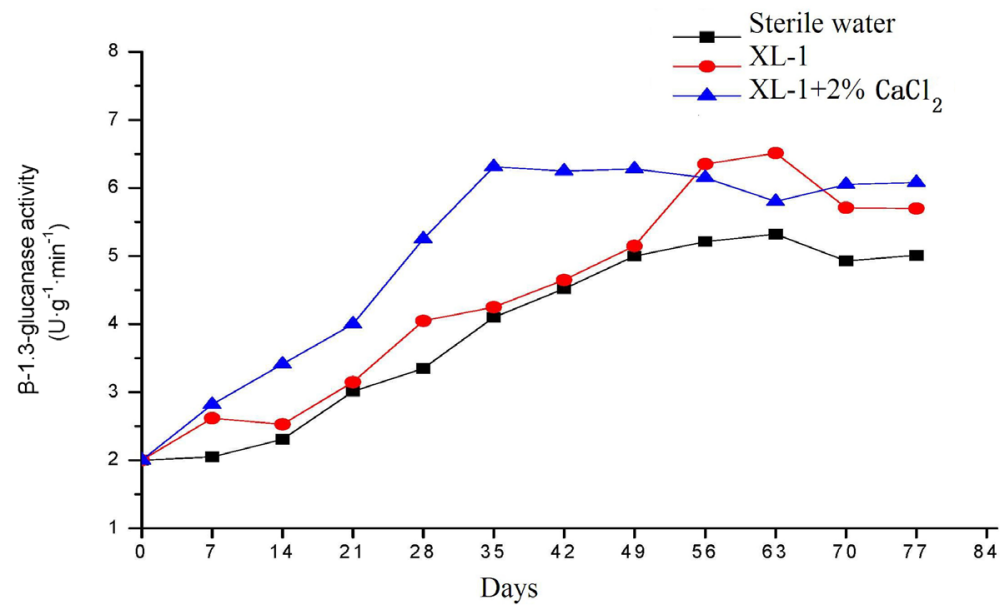

Figure 2. Effect of XL-1 and yeast suspension including $2 \% \mathrm{CaCl}_{2}$ treatment on $\beta$-1,3-glucanase activity.

\section{Effect of $\mathrm{XL}-1$ and $2 \% \mathrm{CaCl}_{2}$ on SOD activity in cantaloupe}

As shown in Figure 3, the SOD activity in cantaloupe with antagonistic yeast XL-1 $+2 \% \mathrm{CaCl}_{2}$ and with only antagonistic yeast showed an increasing-decreasing tendency. The SOD activity of the 3 groups reached its peak on the 7th day and began to decrease after 7 days. However, the decreasing speed of the group that was inoculated with antagonistic yeast $\mathrm{XL}-1+2 \% \mathrm{CaCl}_{2}$ was the slowest, which illustrated that antagonistic yeast obviously improved the SOD activity. 


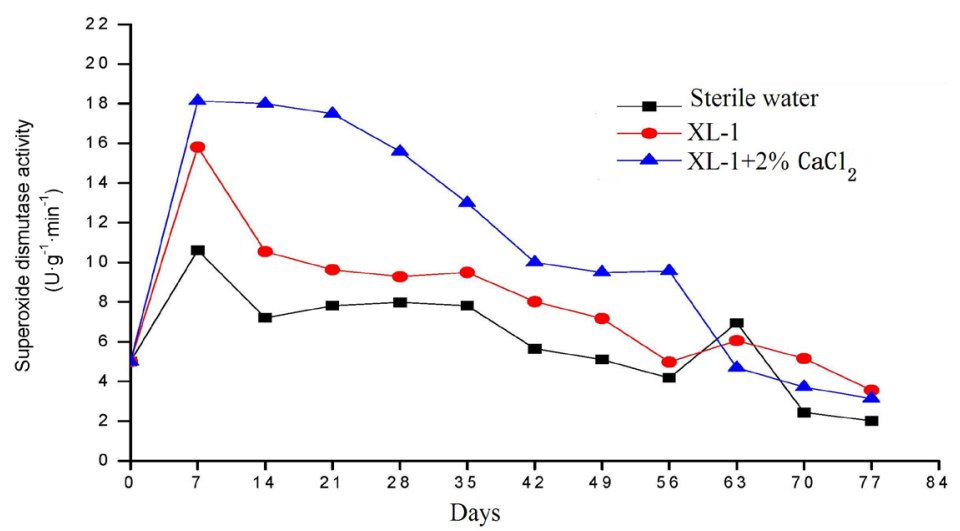

Figure 3. Effect of XL-1 and yeast suspension including $2 \% \mathrm{CaCl}_{2}$ treatment on superoxide dismutase activity in cantaloupe.

\section{Effect of $\mathrm{XL}-1$ and $2 \% \mathrm{CaCl}_{2}$ on POD activity in cantaloupe}

As shown in Figure 4, the POD activity in cantaloupe with antagonistic yeast XL-1 $+2 \% \mathrm{CaCl}_{2}$ and with only antagonistic yeast showed a similar decreasing tendency in the groups that was not significantly different. Based on this, the POD activity in cantaloupe was not influenced by antagonistic yeast.

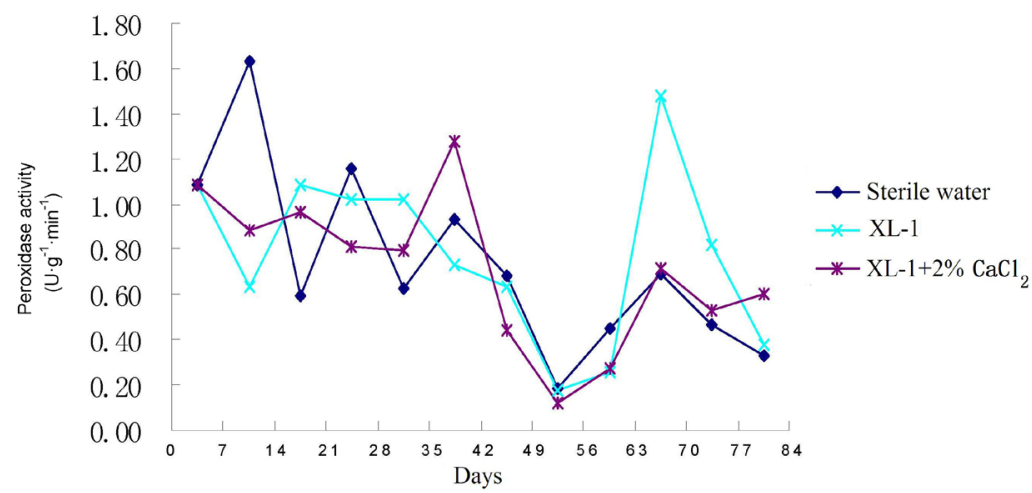

Figure 4. Effect of XL-1 and yeast suspension including $2 \% \mathrm{CaCl}_{2}$ treatment on peroxidase activity in cantaloupe.

\section{DISCUSSION}

Resistance-associated enzymes play important roles during the defense against antagonistic yeast and pathogenic bacteria on fruit and vegetable tissues. The relative physiological and biochemical indicators were induced to change, and the activity of the defense enzymes changed, corresponding with the resistance capacity to pathogenic penetration of the cell wall and cytomembrane in order to block pathogenic bacteria spread and affection (Zhu et al., 1990).

There is an inseparable correlation between PPO and tissue browning, and PPO plays an important role in plant disease resistance. PPO catalyzes the formation of lignin and other 
phenol oxydates to construct a protective shield to resist pathogenic bacteria infection or form quinones to resist diseases. This study demonstrated that inoculating antagonistic yeast XL-1 to treat cantaloupe enhances PPO activity and results in a lower disease rate in cantaloupe and smaller scab diameter, which explains the significant correlation between the antagonistic effect of antagonistic yeast on pathogenic bacteria and the induced PPO activity (Zhang, 1992).

The decreased POD activity is because of the original dynamic balance of tissue being broken by $\mathrm{H}: \mathrm{O}$ accumulation after plant infection. Cells cannot adapt to internal self-modulation of $\mathrm{H}: \mathrm{O}$ accumulation, and the reactive oxygen concentration increases to make the plant suffer its damage. As for the POD effect in plant disease resistance, Qin et al. (2003) reported that there was no distinct correlation between POD activity variance and resistance after peach was infected with Rhizopus stolonifer. This study also demonstrated that inoculating neither antagonistic yeast nor pathogenic bacteria could increase the POD activity in cantaloupe.

$\beta$-1,3-glucanase is a glucanase that can hydrolyze glucans with $\beta$-1,3-glucan bonds. It exists widely in fungus, bacteria, algae, and some plants. It offers disease resistance to an extent, because $\beta-1,3$-glucan is a main component of the fungal cell wall. This study demonstrated that inoculating the antagonistic yeast XL-1 on cantaloupe could increase the $\beta-1,3-$ glucanase activity, which explains the significant relationship between the antagonistic effects of antagonistic yeast on pathogenic bacteria and the increased $\beta$-1,3-glucanase activity (Rabinowitch and Sklan, 1980; Avdiushko et al., 1993).

The SOD activity variance is closely correlated to the movement of oxygen-free radicals, $\mathrm{O}^{2-}$, in cells. Oxygen-free radicals have toxic effects on cells, especially the membrane system. This study showed that the antagonistic yeast XL-1 treatment resulted in increased SOD activity in fruits; the SOD activity in fruits that were inoculated with antagonistic yeast was the highest throughout the whole process, and it did not decrease until the 7th day. Disease outbreaks occur in fruits as the SOD activity gradually enhances. However, fruits that were inoculated with antagonistic yeast + pathogenic bacteria had a later disease outbreak, lower disease rate, and smaller scab diameter than those that were only inoculated with pathogenic

bacteria. Meanwhile, the corresponding SOD activity was steady at a higher level than other fruits, which showed that there is some relationship between cantaloupe disease resistance and SOD activity.

\section{REFERENCES}

Abeles FB and Biles CL (1991). Characterization of peroxidases in lignifying peach fruit endocarp. Plant Physiol. 95 : 269-273.

Avdiushko SA, Ye XS and Kuc J (1993). Detection of several enzymatic activities in leaf prints of cucumber plants. Physiol. Mol. Plant Pathol. 42: 441-454.

Qin GZ, Tian SP, Liu HB and Xu Y (2003). Antagonistic bacteria and pathogen treatment on postharvest peach fruit polyphenol oxidase, peroxidase and phenylalanine ammonia lyase induction. Chin. Agric. Sci. 36: 89-93.

Rabinowitch HD and Sklan D (1980). Superoxide dismutase: A possible protective agent against sunscald in tomatoes (Lycopersicon esculentum Mill.). Planta 148: 162-167.

Schneider S and Ullrich WR (1994). Differential induction of resistance and enhanced enzyme activities in cucumber and tobacco caused by treatment with various abiotic and biotic inducers. Physiol. Mol. Plant Pathol. 45: 291-304.

Zhang ZL (1992). Plant Physiology Experiment Guidance. Higher Education Press, Beijing, 143-144.

Zhu GL, Zhong HW and Zhang AQ (1990). Plant Physiology Experiments. Peking University Press, Beijing, 37-40. 